\title{
Posições de sujeito no campo da educação: de desprestígios, fragilidades e discursos especializados
}

\author{
Paula Corrêa Henning*
}

\section{Resumo}

O presente texto busca trazer alguns dos discursos que circulam por investigações no campo da Educação, anunciando as posições de sujeito no campo dos saberes da Educação. Com a discussão do Triedro dos Saberes em Michel Foucault, pensa-se acerca de certo desprestígio das Ciências Humanas ainda na atualidade, anunciando uma fragilidade teórica no campo da docência. $\mathrm{Na}$ correnteza dessa fragilidade, aparecem os chamados especialistas respaldados na Ciência para ajudar o docente a pensar sobre seu campo de trabalho, sugerindo novas práticas corretas do ser professor. Problematiza-se algumas posições que nos constituem enquanto sujeitos e alguns discursos relativos à nossa profissão das Ciências Humanas.

Palavras-chave: Educação; Posição de sujeito; Trabalho docente.

\section{Subject positions in the education field: from discredits, fragilities and specialized discourses}

\begin{abstract}
The present text seeks to bring some of the discourses that circulate through investigations in the field of Education, announcing the positions of a subject in the field of education knowledge. With the discussion of the Trihedral of Knowledge in Michael Foucault, the text argues about some discredit of the Humanities Sciences (even nowadays), announcing a theoretical fragility in the field of teaching. In the flow of this fragility, the so called specialists appear, based on Sciences to help the teachers think about their working field, suggesting new correct practices to being a teacher. We problematize some positions that build ourselves as subjects and some discourses related to our profession inside the Humanities.
\end{abstract}

Keywords: Education; Subject Position; Teaching.

\footnotetext{
* Professora Doutora e Pesquisadora do Instituto de Educação do Programa de Pós-graduação em Educação Ambiental e do Programa de Pós-graduação de Educação em Ciências da Universidade Federal do Rio Grande (FURG). Rio Grande, Rio Grande do Sul, Brasil.
} 


\section{Introdução}

Como se gestaram as Ciências Humanas? Qual sua posição frente aos diferentes campos de saber? E, diante disso, como se posicionam os participantes dessas ciências? Tais indagações são resultados de um trabalho de tese, finalizado neste ano, com o propósito de discutir as diferentes posições assumidas por sujeitos participantes de pesquisas no campo das Ciências Humanas, especialmente o campo da Educação.

$\mathrm{Na}$ tentativa de mapear diferentes posições, busquei problematizar como alguns pesquisadores vinham dando um lugar específico a seus próprios objetos. Para isso, selecionei como corpus discursivo dessa investigação quatro teses de doutorado defendidas em 2006 pelo Programa de Pós-graduação em Educação da UNISINOS. ${ }^{1}$ O objetivo maior do estudo foi problematizar algumas posições de sujeito que nós, produtores das Ciências Humanas, acabamos por compor no campo da Educação.

Nas pesquisas analisadas, deparei-me com modos de posicionar e posicionar-se frente às questões que moviam aquelas investigações. Mais do que modos originais, autorais ou inéditos, próprios a cada pesquisa, encontrei ali a reiteração de mecanismos próprios à constituição das Ciências Humanas. Mas isso não proveio das descrições convencionalmente produzidas no campo da história das ciências, mas de uma análise minuciosa da própria invenção desse novo campo de saber. Isso equivale a dizer que foi a aproximação com a perspectiva arqueológica desenvolvida por Foucault o que me permitiu mais cuidadosamente olhar para as Ciências Humanas e, paralelamente, para as investigações analisadas, como quem reencontra nelas um movimento de re-fundação do próprio homem.

Querendo mapear o presente texto a partir de problematizações sobre as posições de sujeitos no campo dos saberes das Ciências Humanas, trago à discussão o Triedro dos saberes anunciado por Foucault (2002) e, a partir dessa matriz teórica, anuncio uma espécie de desprestígio das Ciências Humanas. Com isso, trago análises acerca da posição de fragilidade teórica do professorado que, em algumas vezes, se anunciam nas teses. Além disso, mostro como os chamados especialistas de diferentes campos do saber, por estarem respaldados pela Ciência, autorizam-se a auxiliar o professorado que carece de certa teorização sobre seu campo de atuação.

\section{O Triedro dos Saberes e o desprestígio das Ciências Humanas}

Ao pensarmos nas Ciências Humanas como campo científico, ainda nos remetemos, na atualidade, a um campo pouco prestigiado no que se refere à produção de um conhecimento válido e legítimo. Digo isso pensando em alguns relatos que, muitas vezes, ouvi quando falava de minha área de estudos a Pedagogia ou a Educação - ainda muito pouco vista como campo da Ciência. 
Pensando ainda a propósito desse certo desprestígio, digo, com base em Veiga-Neto (2002), que as Ciências Humanas não carregam consigo os quebra-cabeças que compõem seu quadro epistemológico. Nesses campos de saberes, por não tratarmos de objetos mensuráveis e quantitativamente bem definidos, não conseguimos compô-los de esquemas definidos a priori.

Olhando para essas marcas de desprestígio das Ciências Humanas, indaguei-me o quanto o modelo explicativo do Triedro de Saberes - as Ciências Matemáticas e Físicas, as Ciências Empíricas e a Reflexão Filosófica Moderna - anunciado por Foucault (2002), em As Palavras e as Coisas, poderia servir na discussão desse desprestígio.

Percebo que é possível uma aproximação dessas posições de sujeito - no sentido de sermos posicionados como aqueles que participam de um campo científico que não é tão científico assim - das Ciências Humanas com o Triedro dos Saberes de que trata Foucault (2002). Enquanto as demais ciências constituem uma aresta do Triedro dos Saberes, as Ciências Humanas se misturam a todas elas, compondo-se como uma ciência híbrida, misturada, impura. Seu posicionamento híbrido pode estar relacionado ao que Foucault denomina a priori de histórico para emergência das Ciências Humanas: elas somente surgiram quando da junção entre as Ciências Empíricas e a Reflexão Filosófica. Assim, elas somente nascem da união de dois campos legítimos do saber e se fazem híbridas já em sua gestação. E é nessa condição que as Ciências Humanas se gestam, produzindo saberes sobre o homem.

Essa condição híbrida refere-se à própria condição de possibilidade para emergência das Ciências Humanas, pois elas estão relacionadas tanto às Ciências Empíricas quanto à Filosofia Moderna. As Ciências Empíricas exploram a relação do homem com o mundo, pois ele vive, trabalha e fala - sendo, segundo Foucault (2002), esses três objetos as empiricidades que manifestam a atividade humana, tornando o homem o objeto do conhecimento.Em contrapartida, pela Filosofia Moderna, ${ }^{2}$ o homem é, ainda, o fundamento que torna possível a produção de qualquer saber. As Ciências Humanas gestam-se quando se constitui "um duplo empírico-transcedental que se chamou homem" (FOUCAULT, 2002, p. 439).

A Modernidade abandona o Projeto da Similitude - Época Clássica e assume o Projeto da Representação. Um deslocamento do visível para o invisível, da superficialidade para a profundidade, do espaço plano para o espaço volumoso. Da análise da representação dos seres vivos, das riquezas e das palavras na Idade Clássica, vão surgindo as Ciências Empíricas que tomam a vida, a produção e a linguagem como objetos de profundidade. Assim, com a tematização dessas três Ciências Empíricas (Biologia, Economia e Filologia), o homem torna-se objeto de saber, já que, através das empiricidades, podemos conhecê-lo e, ao mesmo tempo, descobri-lo como finito, devido ao seu corpo, 


\title{
Paula Corrêa Henning
}

ao seu desejo e a sua linguagem. Com essa ruptura epistêmica, no final do século XVIII, o homem aparece no campo do saber.

As Ciências Humanas se dão nessa interface das Ciências Naturais com a Filosofia Moderna. Elas são híbridas, mestiças e essa, talvez, seja uma justificativa por ocuparem, ainda hoje, uma posição menos privilegiada do que as demais ciências, afinal, seu ponto constituinte é dado como o volume de um Triedro dos Saberes (FOUCAULT, 2002). O domínio volumoso da episteme moderna se representa em três dimensões, como num triedro: as Ciências Matemáticas e Físicas, as Ciências Empíricas (como Biologia, Economia e Filologia) e a Reflexão Filosófica Moderna. As Ciências Humanas não são uma face do Triedro, são o seu próprio interior, dando volume àqueles três campos dos saberes. Elas se misturam aos demais campos do Triedro, aliás, são os únicos saberes que se misturam, representando um risco para os outros campos: cada saber busca permanecer em sua dimensão própria, preservar suas especificidades, garantir suas fronteiras.

\begin{abstract}
O que explica a dificuldade das 'ciências humanas', sua precariedade, sua incerteza como ciências, sua perigosa familiaridade com a filosofia, seu apoio mal definido sobre os outros domínios de saber, seu caráter sempre secundário e derivado, como também sua pretensão ao universal, não é como freqüentemente se diz, a extrema densidade de seu objeto; não é o estatuto metafísico ou a indestrutível transcendência desse homem de quem elas falam, mas antes a complexidade da configuração epistemológica em que se acham colocadas, sua relação constante com as três dimensões que lhes confere seu espaço. (FOUCAULT, 2002, p. 481) [grifo do autor]
\end{abstract}

Numa leitura moderna, percebo que a tentativa de purificação é uma força na busca de aceitação e legitimidade, tornando as coisas incomunicáveis: de um lado as Ciências Naturais, os laboratórios, os fatos; de outro, as Ciências Humanas, o homem, a sociedade. A intersecção entre as coisas da natureza e as coisas do homem é abolida de um sistema que traz o mundo estilhaçado, repicado, cortado. É então que Latour (2000) nos põe a pensar fomos/somos modernos? Se entendermos a Modernidade como esse tempo que dividiu a natureza e a sociedade, então esse tempo está em crise, quebrado.

Talvez o quadro moderno houvesse conseguido se manter por mais algum tempo caso seu próprio desenvolvimento não houvesse estabelecido um curto-circuito entre natureza, de um lado, e as massas humanas, de outro. Enquanto a natureza permaneceu longínqua e dominada, ainda se parecia vagamente com o pólo constitucional da tradição. Parecia reservada, transcendental, inesgotável, longínqua. Mas como classificar o buraco de ozônio, o aquecimento global do planeta? Onde colo- 
car estes híbridos? Eles são humanos? Sim, pois são nossa obra. São naturais: Sim, naturais porque não foram feitos por nós. (LATOUR, 2000, p. 54)

Daí a grande indagação de Latour. Como sermos modernos sem afastar Deus das leis da natureza e das leis dos homens? Sem glorificar a Revolução Científica e desdenhar do regime antigo? Sem buscar a separação entre racional/irracional, verdade/mentira, ciência/não-ciência? Ele mesmo nos responde: Jamais fomos modernos. Esse mundo não existiu porque não funcionou através de suas regras. Buscou-se a separação entre o natural e o social, mas isso nunca aconteceu. Que separação é essa entre o humano e o natural, já que a ciência, como fatos, verdades e experimentos, é produzida pelo homem? Como conseguir a purificação e a separação total e exclusiva entre um e outro?

Vale ressaltar aqui que essas discussões de Latour (2000) denunciam o desprestígio do humano frente à técnica e reivindicam um lugar para o homem nas ciências, desde sempre, uma vez que o homem estaria implicado na constituição dos saberes. No entanto, a radicalidade da crítica foucaultiana incide mais fortemente sobre a própria invenção do homem na história dos saberes. Diferentemente de buscar um lugar para o humano na paisagem das ciências modernas, Foucault mostra como o próprio homem é, possivelmente, a mais cara invenção da Modernidade, tornando possíveis os binarismos de que trata Latour.

Ao mesmo tempo em que o projeto oficial da Modernidade buscou a purificação das coisas, dos fatos, a realidade nunca se rendeu completamente a ele. Um projeto falido, uma Modernidade - científica e moral - que teve inúmeras dificuldades para concretizar sua utopia. Uma sociedade mais humana, justa, igualitária, livre, fraterna, democrática. Esse foi o sonho da Modernidade. Mas onde encontramos essa sociedade equitativa, esse sujeito autocentrado, essa educação que emancipa? Um projeto que longe de cumprir as promessas a que se destinou, faliu em seus ideais simplesmente porque não há como formarmos para a tal emancipação.

Trazidas essas primeiras problematizações do campo das Ciências Humanas acerca do que venho chamando de certo desprestígio dessas ciências, passo a compor algumas análises acerca da figura de uma suposta fragilidade teórica entre o professorado. Para tratar dessa fragilidade, trago um campo específico que compõe essas ciências: o campo da docência, do professorado. E me limito a ele por dois motivos: o primeiro porque é esse o campo em que se debruçam a maioria das pesquisas aqui colocadas sob análise. Segundo, e talvez o mais importante, porque esse é o meu campo de atuação, onde me sinto mais à vontade para discuti-lo por vivenciá-lo cotidianamente enquanto professora do Ensino Superior. A seguir, gostaria de convidar o leitor a problematizar comigo alguns excertos de Teses de Doutorado recentemente defendidas que nos provocam a pensar numa certa fragilidade teórica que vem compondo o campo da docência. 


\title{
Fragilidades que nos habitam: provocações ao campo da docência
}

Percebi correntemente a presença deste argumento da fragilidade teórica na Tese 1, quando o autor traz para discussão o conteúdo e o endereçamento da Revista Nova Escola. Trata-se de uma revista para

\begin{abstract}
o professor de sala de aula, como aquele que tem por objetivo a simplificação da linguagem acadêmica, chegando ao seu leitor menos iniciado com a indicação de práticas e o projeto de ensinar como fazer, dar dicas, sugestões de práticas. (Tese 1, 2006, p. 75) ${ }^{3}$
\end{abstract}

Com isso, o autor não assume a posição de que ao professor cabe apenas ter dicas do como fazer, mas traz a problematização de que esse artefato cultural vem posicionando o sujeito professor como aquele que se preocupa mais com o como fazer do que com a problematização do seu campo de saber.

Essa questão me chamou muito a atenção através de alguns excertos da Revista Nova Escola, trazidos na Tese 1, em relação ao fato de o professor de Matemática não saber o seu conteúdo, o que ficou evidente. Após trazer esses excertos, o doutorando diz que essa é uma forma preconceituosa de tratar o professor.

\begin{abstract}
Apresenta forma e conteúdo integrados coerentemente, a partir de uma idéia pré-concebida (por que não dizer preconceituosa?) de quem sejam seus leitores e, principalmente, leitoras: profissionais não-suficientemente formados, precisando de explicações simplificadas para seus fazeres pedagógicos. (Tese 1, 2006, p. 98)
\end{abstract}

Será que esses profissionais são tão inocentes e indefesos? Será que a falta de conhecimentos prévios para ser professor de Matemática também não faz parte da sua formação? E se a Revista Nova Escola vende tanto, como anuncia o autor da Tese, será que ela não vem promovendo um discurso ao qual os professores aderem? Afinal, o público já compra e continua comprando a revista, o que leva a pensar que vem gostando de seu conteúdo, ou que, no mínimo, tais conteúdos servem a determinadas necessidades e são postos a funcionar em alguma prática docente. Além disso, os próprios depoimentos que o autor traz de leitores da revista demonstra o quanto essa revista tem aceitação frente ao seu público. Os professores não pensam assim por acaso, senão por força de discursos que também os constituem. O que percebo é que esses discursos vêm produzindo e sendo produzidos pelos professores, e é nessa trama que os modos de ser professor vão sendo feitos.

O discurso do professor não constitui um projeto deliberado de um falante autônomo a partir de uma intenção comunicativa, mas sim que é assumido a partir de uma 
ordem, a partir de um sistema de produção do discurso, a partir de princípios de controle, seleção e exclusão que atuam sobre suas (re)produções de significados e sobre suas práticas específicas. Este aspecto tem sido crucial na reconsideração de atribuições do significado essencial inerente à experiência. (DÍAZ, 1999, p. 15)

Quero com isso dizer que esses discursos de fragilidade teórica, também produzidos por nós, acabam por ganhar espaço nas práticas do professorado, seja por reprodução de juízos morais sobre a competência, seja pela simpática adesão às estratégias que pretendem auxiliar na superação de tal fragilidade. Não há o mocinho e o vilão, há sim "um complexo jogo de relações discursivas" (DÍAZ, 1999, p.19). Existem posições de sujeito que nos fazem e nós mesmos também assumirmos determinados discursos, fazendo-os nossos. Uma ordem do discurso que se produz através de ditos, de suas práticas, de seus rituais, fazendo do professor e ele mesmo se fazendo também como aquele profissional que advém de uma busca incansável por fórmulas fortalecedoras. Aqui a consciência já não funciona como a libertadora dessa trama discursiva. É uma ordem que muito facilmente se dissemina.

Essa talvez seja uma possibilidade do porquê de as Ciências Humanas parecerem sempre estar aquém das Ciências Naturais. Minha preocupação aqui não é defender as pobres Ciências Humanas, mas evidenciar o quanto essas, ainda hoje, se compõem de profissões que se posicionam por discursos de fragilidade teórica. Não percebo na Medicina, por exemplo, seus profissionais estarem atrás de fórmulas mágicas do como procederem em uma cirurgia ou buscarem sugestões de técnicas em periódicos popularizados sobre saúde em geral. Porém, no campo da docência, isso é muito presente. A classe do professorado e aqui situo, por exemplo, as estudantes de Pedagogia, estão sempre buscando novas estratégias do como agir em sala de aula. Pouco percebo nesse curso onde atuo como professora, acadêmicas preocupadas com a problematização das condições que tornam possíveis seus saberes e suas práticas. As preocupações parece versarem mais sobre o como agir no cotidiano das escolas.

Questionando essas situações que vivencio como professora de um Curso de Pedagogia, corroborei minha análise acerca dessa fragilidade teórica do professorado ao perceber recorrentemente em algumas Teses a necessidade constante dos professores - da Educação Infantil, Séries Iniciais do Ensino Fundamental (Tese 2) e professores de Matemática do Ensino Fundamental (Tese 1) - de buscarem a voz de quem está autorizado a falar: o especialista. Ou seja: para tornarem-se bons profissionais, é necessária a procura constante de alguém que oriente o agir pedagógico correto e, em geral, esse especialista é alguém que provém de um campo prestigiado de saber.

Estas professoras observam também que o trabalho realizado nas Classes e Escolas Especiais é melhor e 
Paula Corrêa Henning

mais direcionado, tendo em vista que é feito por especialistas e com número reduzido de alunos (Tese 2 , 2006, p. 73) [grifo meu].

Todos os professores que foram buscar essa ajuda na APAE [instituição de reconhecido saber especializado] encontraram não só ajuda pedagógica, mas palavras de estímulo e incentivo para perseguirem a inclusão de todos os alunos na sala de aula do ensino regular e, principalmente, a certeza de que todos aprendem. (Tese 2, 2006, p. 137) [grifo meu]

Com os excertos acima, percebo o quanto a presença do especialista legitima e confere verdade ao que diz. Mais do que isso: quando dito por especialistas, no caso das professoras de Classes Especiais, temos a certeza de que todos podem aprender, depende tão somente de nós. Quando eles entram em cena, o trabalho é melhor, mais bem direcionado e, arrisco-me a dizer, fazendo da Educação um espaço de maior prestígio e reconhecimento científico. Nesse sentido, muito bem analisa a Tese 1, quando apresenta a presença dos especialistas nas dicas de sucesso para a prática pedagógica de Matemática:

Outro elemento importante é a presença de especialistas que validam duplamente e autorizam a presença dessas práticas no espaço da Revista. (Tese 1, 2006, p.64) [grifo meu]

[...] pode-se deduzir que a Matemática só não é mais difícil no seu ensino e na sua aprendizagem porque existe a Revista a qual, além de tudo, parece também assumir a função simplificadora dos manuais didáticos. Valendo-se de estratégias para convencimento, são apresentadas práticas de muitos professores e professoras dos mais diferentes recantos deste país e, ainda, comentadas a partir de um olhar científico, pela palavra de especialistas da área, que validam, apóiam e sugerem seus textos, na tentativa de tomar esta área do conhecimento mais palpável a todos. (Tese 1, 2006, p.92) [grifo meu]

E quem responde aos questionamentos dos professores e professoras? Especialistas vinculados a centros conceituados em todo País, geralmente a voz de matemáticos e matemáticas que trazem a resposta considerada científica. [...] Analisando o conjunto de textos, constata-se a presença de estratégias discursivas atuando como dispositivos de autolegitimação, credenciando a Revista diante de seus interlocutores. Quem ousaria discordar dos especialistas com as suas sábias explicações. (Tese 1, 2006, p.97) [grifo meu]

Na minha leitura, os discursos, tanto da Revista Nova Escola, quanto dos PCNs, estabelecem uma relação de oposição entre o discurso científico, neste estudo en- 
tendido como aquele produzido pelos matemáticos, e o discurso pedagógico. Instituem uma supremacia do primeiro sobre o segundo, autorizando-se, assim, uma hierarquização das práticas pedagógicas, mesmo entre os próprios professores, posicionando-os diferentemente: aqueles que sabem como pensar e fazer, os especialistas, e aqueles que executam as recomendações. (Tese 1, 2006, p.100) [grifo meu]

Uma vontade de verdade se desenha sobre a ciência e aqui essa ciência é representada por aqueles que desenvolvem saberes sobre um campo específico e práticas pedagógicas a serem desenvolvidas. Foucault (2004), em várias passagens do seu livro $A$ Ordem do Discurso, mostra-nos o quanto a Ciência se situa "no verdadeiro", naquele discurso que é capaz de nos desvelar o mundo, nos mostrar como agir e, assim, melhorar nossa atuação profissional. A preocupação aqui não é com a veracidade do que é dito pela ciência, mas na forma como seu discurso nos captura e se posiciona "no verdadeiro". Assim, "uma proposição deve preencher exigências complexas e pesadas para poder pertencer ao conjunto de uma disciplina; antes de poder ser declarada verdadeira ou falsa, deve encontrar-se, como diria M. Canguilhem, 'no verdadeiro'" (FOUCAULT, 2004, p.33, grifo do autor).

Essa seleção do discurso é produzida a partir de procedimentos que colocam alguns ditos "no verdadeiro" e outro não. Além do campo de saber que circula nesses ditos, há também um fator imprescindível para assumir um determinado lugar na ordem do discurso: quem disse, quem está autorizado a dizer. Com isso, percebo o quanto a presença dos professores convidados a responder as perguntas dos leitores na Revista Novas Escola - de que trata a Tese 1, ou os professores das Classes Especiais - de que trata a Tese 2, ditos como especialistas no assunto sobre aprendizagem dos alunos com necessidades educativas especiais, posicionam num lugar privilegiado para dizer e serem ouvidos. O lugar privilegiado parece ser o campo da verdade científica. Existe um controle dos enunciados sendo produzido pela ciência. Para isso, não pode ser qualquer um a falar: é preciso que este esteja "no verdadeiro", que esteja qualificado para dizer a verdade, para auxiliar nas práticas.

[...] um controle que não incide, pois, sobre o conteúdo dos enunciados, sobre sua conformidade ou não com certa verdade, mais sobre a regularidade das enunciações. 0 problema será quem falou e se era qualificado para falar, em que nível se situa esse enunciado, em que conjunto se pode colocá-lo, em que medida ele é conforme as outras formas e outras tipologias de saber. (FOUCAULT, 2005, p.220, grifo meu)

O que quero trazer à discussão é o quanto na Tese 1 e $2^{4}$ esses especialistas, em nome da ciência, são chamados a auxiliar o professorado para melhoria de suas práticas pedagógicas. Mais uma vez a posição de sujeito 


\title{
Paula Corrêa Henning
}

dos docentes, não raras vezes, é colocada em um lugar que assume a docência como espaço do que deve ser feito e não um espaço do pensar sobre como fazer. Pereira e Ratto (2006), ao apresentarem uma pesquisa sobre as obras mais utilizadas em trabalhos da ANPED, no período de 1998 a 2000, demarcam um "fundamentalismo pedagógico" que acaba por compor o professorado, determinando suas formas de ser, viver e agir pedagogicamente. Nas palavras dos autores:

\begin{abstract}
O professorado, pouco a pouco, deixa de se perguntar pelo que pode fazer, pelo que sabe fazer, pelo que consegue fazer e, em lugar disso, pergunta pelo que é que deve fazer. Pouco a pouco transfere o poder de decisão e orientação para uma instância exterior a si. Fabrica uma transcendência a quem se põe a seguir. Agrega teorias, experiências de outros, palestras, leituras, programas, planos, e com tudo isso inventa uma bíblia imaginária para seguir. (PEREIRA; RATTO, 2006, p. 8)
\end{abstract}

Olhando para esses discursos sobre os especialistas presentes para direcionar a prática do professorado, percebo o quanto, com a Ciência, nos apropriamos de um saber válido, de um saber que entra na ordem para nos dizer, com propriedade, como sermos bons professores. Com o campo de saber da ciência fazemos funcionar a produção de certas regras e leis, conservando alguns ditos e excluindo outros.

Posicionados em lugar privilegiado, os especialistas podem dar dicas no auxílio de suas ações profissionais. Vendo isso, percebi, em algumas Teses, que, em razão de o pesquisador estar assumindo, no ato da investigação, um espaço também privilegiado, pois é aquele que detém o conhecimento, advindo da Universidade - lócus privilegiado de produção científica - os sujeitos da pesquisa o colocam nessa posição conferida ao especialista. Talvez, por isso, constatei que, em algumas Teses, os sujeitos da pesquisa confessam-se a esses pesquisadores, anunciando suas angústias, medos e culpas por não serem aquele profissional que deveriam ser.

\section{Algumas provocações finais...}

Com essas posições demarcadas aos e pelos partícipes das Ciências Humanas, creio ser importante problematizarmos os lugares que vimos ocupando nessa paisagem científica contemporânea. Mas, para isso, é preciso um alerta, inicialmente: "Para recusar e criticar o que somos, devemos, ao menos num sentido mínimo, ter descoberto o que somos ou como somos constituídos e ter imaginado e inventado que novos tipos de sujeito poderíamos ser" (DEACON; PARKER, 2000, p. 107).

As constituições das posições de sujeito que vimos ocupando nas tramas discursivas não são aleatórias, elas fazem parte de uma rede num solo 
positivo. E esse solo é a episteme moderna. Aquela que produz as formas de sermos e estarmos nesse mundo. Com isso, quero dizer que as posições que hoje ocupamos não são dadas ao natural. A fabricação do sujeito professor, do sujeito pesquisador, constitui a experiência que podem ter de si mesmos, sendo marginados por determinadas regras, normas que são determinadas pela própria episteme. Ali se produzem discursos que definem a verdade sobre o sujeito, as posições por ele ocupadas ou, então, que devam ser ocupadas, posicionando-os em determinados lugares, supostamente ideais e necessários para serem bons professores, bons pesquisadores, enfim, para serem bons nas diferentes posições de sujeito que ocupam.

Essa constituição do sujeito não é dada de uma forma passiva, como se fossem vítimas de serem posicionados como profissionais frágeis teoricamente, por exemplo. A constituição do sujeito não é silenciosa de nossa parte, sendo apenas impregnada em nós por tais discursos. Muito pelo contrário. Somos "sujeitos falantes; não como objetos examinados, mas como sujeitos confessantes; não em relação a uma verdade sobre si mesmos que lhes é imposta de fora, mas em relação a uma verdade sobre si mesmos que eles mesmos devem contribuir ativamente para produzir" (LARROSA, 2000, p. 55). Os sujeitos são tomados por esses discursos e os acolhem como verdadeiros, colocando-os em funcionamento na produção das Ciências Humanas.

Com isso, quero dizer que os discursos que circulam na atualidade sobre a Educação, como uma ciência humana, não são dados por acaso. São constituições nossas que acolhemos e fazemos funcionar como verdade. Com essas produções, determinamos modos de existir tanto no campo dos saberes quanto no campo da moral. Desta problematização é possível perceber que as inúmeras posições que ocupamos enquanto sujeitos da educação não são posições determinadas ou então posições que são únicas e exclusivamente de um determinado sujeito. São, antes, discursos que vão nos posicionando e nos convocando a tomar posição. Se entendermos esses discursos como contingentes a uma história produzida, podemos inventar outras formas de estar no mundo. Podemos exercer uma liberdade que nos possibilite olhar para nós mesmos de outra maneira, de pensar diferentemente do que se pensa e de ser diferentemente do que se é.

Conquistamos certa liberdade para a produção de nós mesmos, para a possibilidade de transformarmos aquilo que não nos agrada, sendo possível olhar de outra maneira, ou como diz Foucault (1995, p. 239), "recusar o que somos". Isso me lembra o pensamento do autor sobre a filosofia, entendendo-a como um movimento de desprendimento das regras já estipuladas para o jogo, hesitando aceitar os valores já determinados e, com isso, forçarmos a experiência de pensarmos a partir de outros olhares (FOUCAULT, 2006).

Por isso, analisando as posições de sujeito que hoje ocupamos, penso que o exercício do ensaio faz-se necessário, para que possamos exercitar 
em nós mesmos a possibilidade de o sujeito pensar sobre si, de explorar o pensamento e criar estratégias de pensar o estranho, aquilo que escapa às categorias da tradição, que escapa aos discursos já instaurados.

O "ensaio" - que é necessário entender como experiência modificadora de si no jogo da verdade, e não como apropriação simplificadora de outrem para fins de comunicação - é o corpo vivo da filosofia, se, pelo menos, ela for ainda hoje o que era outrora, ou seja, uma "ascese", um exercício de si, no pensamento (FOUCAULT, 2006, p.13).

Exercer sobre nós mesmos outra forma de viver, lutar para romper com estratégias de governo da conduta que muitos discursos exercem sobre nós. Se esses discursos que circulam precisam que os aceitemos e os incorporemos como nossos, temos a possibilidade de romper com eles e traçar, talvez, aquilo que Nietzsche (2002) nos anunciou ser sua vida: um ensaiar e perguntar. Essa talvez seja a possibilidade para nos indagarmos acerca daquilo que nos tornamos e ensaiar outras possibilidades de vida.

\section{Referências}

DEACON, R.; PARKER, B. Educação como sujeição e como recusa. In: SILVA, T. T. da (Org.). O sujeito da educação: estudos foucaultianos. 4. ed. Petrópolis: RJ: Vozes, 2000.

DÍAZ, M. Foucault, docentes e discursos pedagógicos. In: SILVA, T. T. da (Org.). Liberdades reguladas: a pedagogia construtivista e outras formas de governo do eu. Petrópolis, RJ: Vozes, 1999.

FOUCAULT, M. O sujeito e o poder. Apêndice da 2. ed. Michel Foucault entrevistado por Hubert L. Dreyfus e Paul Rabinow. In.: DREYFUS, H.; RABINOW, P. Michel Foucault, uma trajetória filosófica: para além do estruturalismo e da hermenêutica. Rio de Janeiro: Forense Universitária, 1995.

. As palavras e as coisas: uma arqueologia das ciências humanas. 8. ed. São Paulo: Martins Fontes, 2002.

. A ordem do discurso. 10. ed. São Paulo: Loyola, 2004.

Em defesa da sociedade: curso no Collège de France (1975-1976). 4. tiragem. São Paulo: Martins Fontes, 2005.

. História da sexualidade 2: o uso dos prazeres. 11. ed. Rio de Janeiro: Graal, 2006.

LARROSA, J. Tecnologias do Eu. In: SILVA, T. T. da (Org.). O sujeito da educação: estudos foucaultianos. 4. ed. Petrópolis, RJ: Vozes, 2000.

LATOUR, B. Jamais fomos modernos. São Paulo: Editora 34, 2000. 
NIETZSCHE, F. Assim falou Zaratustra. São Paulo: Martins Claret, 2002.

PEREIRA, M. V.; RATTO, C. G. A formação de professores e o fundamentalismo pedagógico. ENDIPE 2006. Disponível em: <http:// www.13endipe.com/ paineis/paineis_autor/T1375-1.doc>. Acesso em: 04 out. 2007.

VEIGA-NETO, A. Paradigmas? Cuidado com eles! In: COSTA, M.; VORRABER. (Org.). Caminhos investigativos II: outros modos de pensar e fazer pesquisa em educação. Rio de Janeiro: DP\&A, 2002.

\section{Notas}

1 Neste artigo trago excertos de apenas duas Teses por entender que estes são os mais significativos para colocá-los em exame. Certamente, nas demais Teses, encontramos substratos importantes diante da fragilidade teórica do professorado. No entanto, buscando recortar e anunciar excertos que identifiquem a análise que venho realizando, escolho alguns recortes e não outros.

$2 \mathrm{O}$ que trato por Filosofia Moderna aqui se refere à Filosofia Transcendental de Kant, matriz de todos os desdobramentos éticos e políticos daquele momento histórico.

${ }^{3}$ Querendo dar destaque aos excertos do corpus discursivo, optei por colocá-los em itálico.

${ }^{4}$ Preciso deixar claro que, na Tese 2, a chamada dos especialistas é como uma forma de exaltação a esses profissionais que detêm o saber dos alunos com necessidades educativas especiais, enquanto que na Tese 1 o autor faz uma crítica a esse chamamento dos especialistas para dizer, enfim, que prática pedagógica na Matemática deve ser exercida. De qualquer forma, exalto aqui a problemática dos especialistas no campo da educação, especialmente para aqueles profissionais que trabalham direto em sala de aula. Minha análise versa aqui tanto dos discursos que professam a Tese 2, quanto do objeto estudado pela Tese 1: a Revista Nova Escola, pois seja num caso ou em outros, esses discursos circulam pela sociedade.

\section{Correspondência}

Paula Corrêa Henning - Rua Triunfo, 3189, Bairro Laranjal, Pelotas/RS. CEP: 96090-790.

E-mail: paula.henning@ig.com.br.

Recebido em 12 de setembro de 2009.

Aprovado em 15 de abril de 2010. 